\title{
Polysulfone Membranes Based Hybrid Nanocomposites for the Adsorptive Removal of Hg(II) Ions
}

\author{
Abeer M. Alosaimi
}

Citation: Alosaimi, A.M

Polysulfone Membranes Based Hybrid Nanocomposites for the Adsorptive Removal of $\mathrm{Hg}$ (II) Ions Polymers 2021, 13, 2792. https:// doi.org/10.3390/polym13162792

Academic Editor: Alberto Figoli

Received: 25 July 2021

Accepted: 17 August 2021

Published: 19 August 2021

Publisher's Note: MDPI stays neutral with regard to jurisdictional claims in published maps and institutional affiliations.

Copyright: (C) 2021 by the author Licensee MDPI, Basel, Switzerland. This article is an open access article distributed under the terms and conditions of the Creative Commons Attribution (CC BY) license (https:// creativecommons.org/licenses/by/ $4.0 /)$
Department of Chemistry, College of Science, Taif University, P.O. Box 11099, Taif 21944, Saudi Arabia; a.alosaimi@tu.edu.sa

\begin{abstract}
Organic-inorganic nanoparticles, which can improve and modify the mechanical and chemical properties of polymers, have been used as fillers to prepare high-performance hybrid nanocomposite membranes. In this study, we explored whether the incorporation of organic nanofillers (graphene $(\mathrm{G})$, graphene oxide $(\mathrm{GO})$, carbon nanotubes (CNTs), or oxidized carbon nanotubes (CNTOxi)) into polysulfone (PSF) and montmorillonite (MMt)-modified PSF membranes could enhance membrane performance for the removal of heavy metal ions from contaminated solutions. These hybrid membranes were prepared by a phase inversion method using chloroform as the solvent. The surface morphologies of the membranes revealed good dispersibility of the organoclay and carbon nanomaterials in the PSF matrix. The hybrid nanocomposite membranes showed significantly improved thermal stability and mechanical properties as compared to the pristine PSF and PSF/MMt membranes. The adsorption efficiencies of these hybrid adsorptive membranes for $\mathrm{Hg}(\mathrm{II}), \mathrm{Pb}(\mathrm{II}), \mathrm{Sr}(\mathrm{II}), \mathrm{Fe}(\mathrm{III}), \mathrm{Zn}(\mathrm{II}), \mathrm{Ni}(\mathrm{II}), \mathrm{Al}(\mathrm{III}), \mathrm{Co}(\mathrm{II}), \mathrm{Y}(\mathrm{III})$, and $\mathrm{Cr}(\mathrm{III})$ were investigated. The PSF/MMt/CNTOxi and PSF/MMt/GO membranes exhibited the highest adsorption efficiencies. In particular, these adsorptive membranes showed selectivity toward $\mathrm{Hg}(\mathrm{II})$, and the $\mathrm{Hg}(\mathrm{II})$ extraction percentage was maximized at $\mathrm{pH}$ 2. The maximum $\mathrm{Hg}$ (II) adsorption capacities of PSF/MMt/CNTOxi and PSF/MMt/GO were 151.36 and $144.89 \mathrm{mg} / \mathrm{g}$, respectively, and the adsorption isotherm was in approval with the Langmuir model. These hybrid nanocomposites can be used in water purification application.
\end{abstract}

Keywords: hybrid nanocomposites; polysulfone; clay; graphene oxide; carbon nanotube; heavy metal removal

\section{Introduction}

In recent years, membrane separation technology has been developed for use in advanced water treatment processes and has played an important role in reducing water pollution [1-4]. However, water pollution remains an issue because of the continued growth in the number of new organic compounds used in commercial products such as pharmaceuticals, personal care products, and pesticides, as well as the use of toxic heavy metals that can affect human health [5-7]. As a result, the availability of clean water for daily life and for agricultural and industrial use has become a global challenge. Moreover, owing to the huge diversity of pollutants, many conventional membrane materials for wastewater treatment are no longer feasible, and the development of new approaches is an ongoing challenge in the field of membrane technology.

Polymeric membranes are commonly used for separation technology owing to their good physicochemical properties, environmental friendliness, effectiveness, and low fabrication costs. In particular, remarkable progress has been made in the field of heavy metal removal from industrial wastewater using polymeric nanocomposite membranes, and considerable research efforts have been focused on the synthesis of membranes with high efficiencies for water purification [8,9]. Polysulfone (PSF) is one of the most popular polymers for use in ultrafiltration membranes because of its high mechanical strength, excellent thermal stability, and superior chemical resistance over the entire $\mathrm{pH}$ 
range [10-12]. However, PSF has a lower surface energy and higher hydrophobicity than other hydrophilic polymer membranes, which hinders the performance of PSF membranes in treating wastewater and other pollutants. Numerous efforts have been made to enhance the hydrophilicity of PSF membranes and overcome the serious fouling issue, including surface modification, coating, and hydrophilic polymer blending.

Recently, organic-inorganic materials have been used to prepare hybrid membranes with excellent properties and a wide range of applications [13,14]. For example, $\mathrm{Wu}$ et al. prepared a $\mathrm{SiO}_{2}$-graphene oxide (GO) nanohybrid/PSF membrane to improve water permeability [15]. Chai et al. embedded $\mathrm{Fe}_{3} \mathrm{O}_{4} / \mathrm{GO}$ in PSF to enhance permeability and humic acid rejection [16]. To date, many inorganic nanoparticles have been incorporated in the fabrication of membranes, including metal oxides, zeolites, and clay $[17,18]$. In particular, clay has attracted recent interest as a filler in composites because of its low cost, environmental friendliness, and abundance. Polymer-clay nanocomposites have been demonstrated to have various industrial, technological, and electronic applications, and have been widely used for water purification because clay can enhance the properties of polymer matrices, even when added in small amounts, such as the hydrophilicity property, and improves the efficiency of the polymer matrix for pollutant removal in aqueous systems [19-22].

Among the many types of clay used in polymer-clay nanocomposites, montmorillonite (MMt) is the most common clay mineral for the preparation of filtration membrane nanocomposites. Many studies have demonstrated that the addition of MMt improves the properties of filtration membranes, including the surface hydrophilicity, water permeability, pore structure, and thermal and mechanical properties [23]. However, similar to other clays, MMt is naturally hydrophilic, hindering its interactions with and distribution in most types of polymers, which are typically hydrophobic. To improve compatibility, $\mathrm{MMt}$ can be treated with organic cations, called surfactants, before being mixed with a polymer to form a nanocomposite membrane. The ion exchange method is a traditional and simple method for modifying layered silicate surfaces, in which cations between the silicate layers are replaced with organic cations [24], thus allowing MMt to be compatibilized with a polymer matrix. However, the incorporation of inorganic nanoparticles into polymer matrices only results in a limited improvement in properties. Therefore, the introduction of carbon nanomaterials such as GO, carbon nanotubes (CNTs), and $\mathrm{C}_{60}$ to produce novel nanohybrid materials has also been investigated.

Compared with graphene $(\mathrm{G})$ and other carbon nanomaterials, GO is attractive as a nanofiller for the preparation of nanohybrid membranes because of its unique properties, such as a high surface area and excellent physical properties [25-28]. Further, different forms and hybrid/composite structures of GO can be designed [29]. The surface of GO has hydrophilic oxygen-containing functional groups that can adsorb organic species via various mechanisms, including electrostatic interactions and ion exchange [30,31]. For example, GO was introduced into a PSF ultrafiltration membrane to improve hydrophilicity and antifouling abilities of the membrane for water treatments as adsorbent of a mixture of selected organic contaminants of environmental relevance [32]. In addition, a GO-based polymer membrane was used as a filtration or adsorptive membrane for $\mathrm{Hg}$ separation from wastewater [33].

CNT-polymer nanocomposites have also attracted attention for many applications, including membrane technology, because CNTs possess excellent physicochemical properties that can improve the performance of polymeric materials [34]. Additionally, CNTs have been used as nanosorbents for water treatment because of their high adsorption capacities for organics [35]. Xu et al. embedded raw CNTs and oxide-functionalized CNTs in PSF to produce nanocomposite membranes with enhanced properties and filtration performance [36]. Further, pristine CNTs can be functionalized to enhance the chemical reactivity of the surface, and the effect of CNT carboxylation on the properties of nanocomposite polymer membranes has been investigated [3,37-39]. 
In this study, we investigated the preparation of hybrid nanocomposites, in which both MMt and carbon nanomaterials were incorporated as high-performance polymer adsorptive membranes. PSF hybrid nanocomposites were prepared using the phase inversion method. Organic nanofillers (G, GO, CNTs, or oxidized carbon nanotubes (CNTOxi)) were added to MMt-modified PSF in fixed proportions. The morphology, mechanical properties, and thermal stability of the composite membranes were evaluated to obtain a better understanding of the effects of MMt and G, GO, CNTs, or CNTOxi on the physicochemical properties of the membrane. Finally, the analytical potential of the adsorptive membranes for the selective extraction of several heavy metal ions, especially $\mathrm{Hg}$ (II), was explored.

\section{Experimental Details}

\subsection{Chemicals and Reagents}

Polysulfone pellets having a molecular weight of 60,000 were purchased by ACROS ORGANICS CO. Carbone materials (G, GO and MWCNT) were purchased from Nanotechnology CO. LTD Egypt. Montmorillonite-modified nanoclay by $25-30 \%$ trimethylstearylammonium salt. Chloroform, nitric acid, sulfuric acid, and stock standard solutions of $1000 \mathrm{mg} \mathrm{L}^{-1} \mathrm{Sr}$ (II), $\mathrm{Co}$ (II), Zn(II), $\mathrm{Pb}$ (II), $\mathrm{Al}(\mathrm{III}), \mathrm{Y}$ (III), $\mathrm{Cr}$ (III), $\mathrm{Fe}$ (III), $\mathrm{Ni}$ (II) and $\mathrm{Hg}$ (II)were purchased from Sigma-Aldrich (Milwaukee, WI, USA) and were used without any further purifications.

\subsection{Acid Treatment of CNTs}

The carboxylation treatment by acid oxidization [40]: $5 \mathrm{mg}$ MWCNT was added into $6.5 \mathrm{~mL}$ a mixture of nitric acid/sulfuric acid (1:3 in volume) and refluxed at $80{ }^{\circ} \mathrm{C}$ for $3 \mathrm{~h}$. Then the mixture was introduced in an ultrasonic bath for $2 \mathrm{~h}$ at ambient condition. After dilution with DI water, the MWNTs were filtrated through a $0.45 \mu \mathrm{m}$ Millipore nylon filter membrane. Then the product was washed by distilled water until the $\mathrm{pH}$ of the filtrate reached near neutral and then dried at $80^{\circ} \mathrm{C}$ in a vacuum oven for $24 \mathrm{~h}$.

\subsection{Preparation of Hybrid Nanocomposite Membranes}

Polysulfone/Organoclay/Organic nanofiller (G, GO, CNTs, or CNTOxi) hybrid membranes were fabricated by the phase inversion method. First, PSF (4 g) was dissolved in a suitable amount of chloroform under constant stirring at room temperature to form homogeneous solution. Then, MMt and graphene particles ( $2.5 \%$ wt for each one) were dispersed in chloroform, each separately, and sonicated for $10 \mathrm{~min}$ until forming a clear homogenous suspension. Then they were added to the PSF solution. Next, the mixture was stirred for $30 \mathrm{~min}$. After that, this solution was cast onto a glass blade (mold). Finally, the membranes were dried at room temperature for evaporation of $\mathrm{CHCl}_{3}$ and yielded homogenous films. The membrane thickness was approximately $25 \mu \mathrm{m}$. This procedure was used with each of the following organic nanofillers (GO, CNTs, or CNTOxi). The sample's composition is shown in Table 1.

Table 1. Suggested list of abbreviations, codes and compositions for the fabricated materials.

\begin{tabular}{cccc}
\hline Code & $\begin{array}{c}\text { Clay } \% \\
(\mathbf{g})\end{array}$ & $\begin{array}{c}\text { Carbon-Filler Loading } \\
\mathbf{( \% )}\end{array}$ & $\begin{array}{c}\text { Carbon-Filler Loading } \\
(\mathbf{g})\end{array}$ \\
\hline Pure PSF & - & - & - \\
PSF/MMt & $5(0.2)$ & - & - \\
PSF/MMt/G & $2.5(0.1)$ & 2.5 & 0.1 \\
PSF/MMt/GO & $2.5(0.1)$ & 2.5 & 0.1 \\
PSF/MMt/CNTs & $2.5(0.1)$ & 2.5 & 0.1 \\
PSF/MMt/CNTOxi & $2.5(0.1)$ & 2.5 & 0.1 \\
\hline
\end{tabular}

\subsection{Adsorption Method Procedure}

For adsorption tests, we followed the procedure as mentioned in the literature on our samples [7]. Briefly, stock solutions of $\mathrm{Hg}$ (II), $\mathrm{Pb}$ (II), $\mathrm{Sr}(\mathrm{II}), \mathrm{Fe}(\mathrm{III}), \mathrm{Zn}(\mathrm{II}), \mathrm{Ni}(\mathrm{II}), \mathrm{Al}(\mathrm{III})$, $\mathrm{Co}(\mathrm{II}), \mathrm{Y}(\mathrm{III})$, and $\mathrm{Cr}(\mathrm{III})$ were prepared in $18.2 \mathrm{M} \Omega \cdot \mathrm{cm}$ distilled deionized water and 
stored in the dark at $4{ }^{\circ} \mathrm{C}$. For selectivity study of all the prepared membranes in this study, standard solutions were prepared with $5 \mathrm{mg} / \mathrm{L}$ of each metal ion and the $\mathrm{pH}$ of the solutions was adjusted from 1.0 to 9.0 using the appropriate buffer solutions. All standard solutions were individually mixed with $25 \mathrm{mg}$ PSF/MMt/CNTOxi and/or PSF/MMt/GO in order to study the effect of $\mathrm{pH}$ on the selectivity of these material adsorptions across $\mathrm{Hg}^{+2}$ ion. A mechanical shaker was applied for all mixtures for $1 \mathrm{~h}$ at $170 \mathrm{rpm}$ at room temperature. Regarding the study of the adsorption capacity of $\mathrm{Hg}^{+2}$ under batch conditions, standard solutions of $5,10,15,20,25,50,100,125,175,200$, and $250 \mathrm{mg} / \mathrm{L} \mathrm{Hg}^{+2}$ were prepared as the above procedure and adjusted to the optimum $\mathrm{pH}$ value of 2.0 and individually mixed with $25 \mathrm{mg}$ PSF/MMt/CNTOxi and/or PSF/MMt/GO using a mechanical shaker.

\subsection{Instrumentation}

The membranes were also studied by Fourier transform infrared (FTIR) spectra within the wavelength range $500-4000 \mathrm{~cm}^{-1}$ and were obtained using a Bruker Vertex $80 \mathrm{v} \mathrm{spec}-$ trometer at room temperature. The morphology of the membranes was investigated by the scanning electron microscopy (SEM) using an JEOL instrument (JSM-6390LA) with EDX. The membrane samples were sputter coated with $\mathrm{Au}$ atoms, and the surface and crosssection of the membranes were studied by SEM at $5.0 \mathrm{kV}$. XRD patterns were performed for the nanocomposite membranes, which were obtained using Bruker diffractometer (Bruker D8 advance target) under the following conditions: $40 \mathrm{kV}-30 \mathrm{~mA} ; \mathrm{Cu} \mathrm{K} \alpha$ radiation $(\lambda=1.54060 \AA)$; and at a rate of $0.6^{\circ} / \mathrm{min}$ in the range from 5 to $80^{\circ}(2 \theta)$. Thermogravimetric (TG) analyses of the membranes were performed using a Shimadzu Thermal Analyzer under a nitrogen atmosphere, in the temperature ranging from the room temperature to $800{ }^{\circ} \mathrm{C}$.

Mechanical response of the materials was studied by using Universal Testing Machine model GTTGS-2000 at a crosshead speed of $1.0 \mathrm{~mm} / \mathrm{min}$, according to ASTM D-3039. The size of the sample was $10 \mathrm{~cm}$ in length and $1.5 \mathrm{~cm}$ in width. Impact test was carried out using Zwick Pendulum Tester Model 5101, charpy method on samples with dimension of $6.5 \times 1.2 \mathrm{~cm}$. The pendulum energy of $2 \mathrm{~J}$ was used for all the samples. The test was conducted according to ASTM D252. The values of properties were reported based on the average of five measurements for each sample.

Inductively Coupled Plasma Optical Emission Spectrometry (ICP-OES) measurements were obtained by use of a Perkin Elmer ICP-OES model Optima 4100 DV, USA. The ICPOES spectrometer was used with the following parameters: FR power, $1300 \mathrm{~kW}$; frequency, 27.12 MHz; plasma gas (Ar) flow, $15.0 \mathrm{~L} / \mathrm{min}$; auxiliary gas (Ar) flow, $0.2 \mathrm{~L} / \mathrm{min}$; nebulizer gas (Ar) flow, $0.8 \mathrm{~L} / \mathrm{min}$; nebulizer pressure, 2.4 bar; sample pump flow rate, $1.5 \mathrm{~mL} / \mathrm{min}$; integration time, $3 \mathrm{~s}$; and wavelength range of monochromator, $165-460 \mathrm{~nm}$.

\section{Results and Discussion}

\subsection{Characterization of Hybrid Nanocomposite Membranes}

\subsubsection{Fourier Transform Infrared (FTIR) Spectroscopy}

The dispersion of organic and inorganic particles in the polymer matrix plays an important role in the performance of hybrid membranes and is considered one of the greatest challenges in their development. FTIR spectra of the hybrid membrane nanocomposites were collected from 4000 to $400 \mathrm{~cm}^{-1}$, as shown in Figure 1. In the FTIR spectrum of PSF, the peak at $1236 \mathrm{~cm}^{-1}$ is attributed to the stretching vibration of $\mathrm{C}-\mathrm{O}-\mathrm{C}$ groups, the peaks at 1480 and $1585 \mathrm{~cm}^{-1}$ are associated with the skeletal vibrations of aromatic hydrocarbons, and the peaks at 1154 and $1305 \mathrm{~cm}^{-1}$ are assigned to the symmetric and asymmetric stretching of sulfone groups $[4,41]$. The spectral characteristics of the composite materials were very similar to those of PSF, which indicates that there were no interactions between the PSF chains and the various nanofillers. The FTIR spectrum of PSF/MMt/CNTOxi exhibited a characteristic carbonyl peak at $1743 \mathrm{~cm}^{-1}$ corresponding to the carboxylic groups in CNT-COOH and a band at $3639 \mathrm{~cm}^{-1}$ corresponding to hydroxyl groups [34]. The FTIR spectrum of the PSF/MMt/GO membrane showed a distinct carbonyl peak at 
$1738 \mathrm{~cm}^{-1}$ and a broad band at $3624 \mathrm{~cm}^{-1}$, which suggests that a hydrophilic layer was formed on the surface of the membrane owing to the hydrophilic functional groups of GO $[11,28]$.

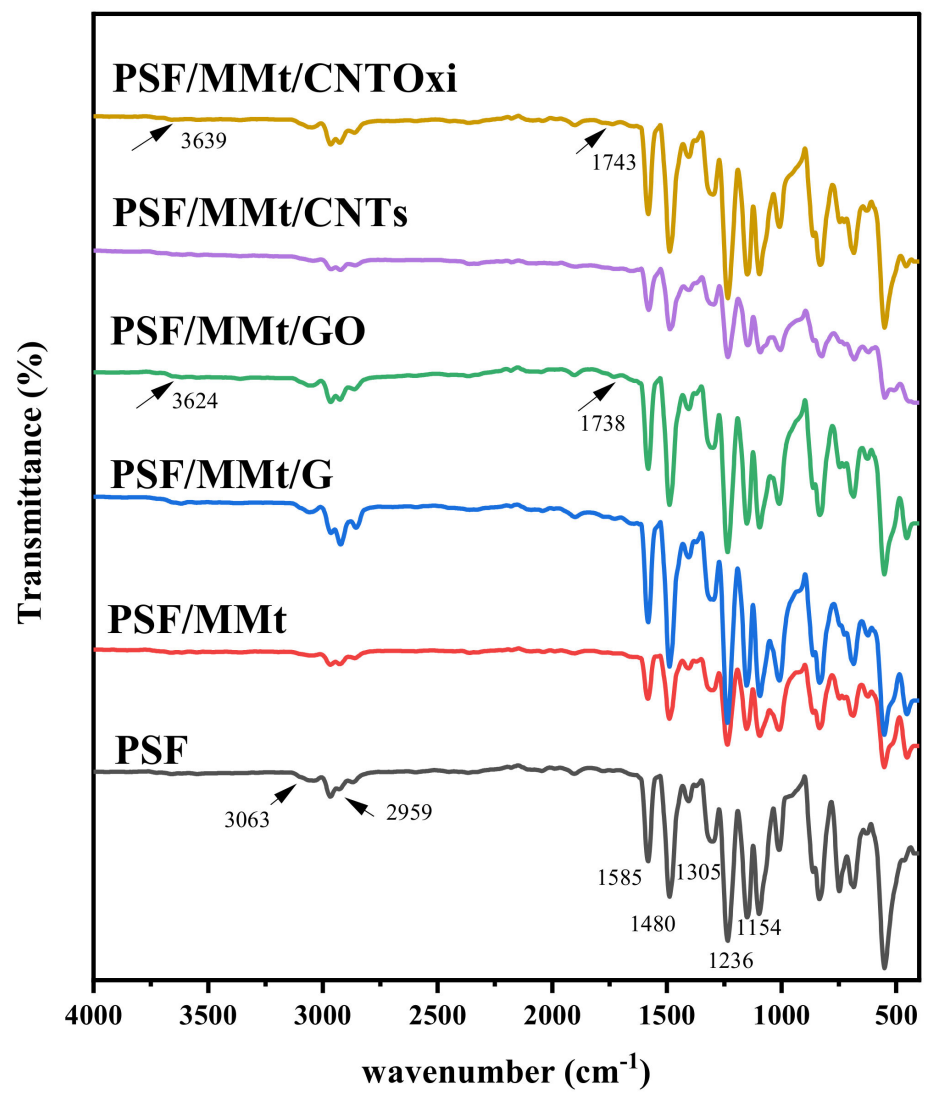

Figure 1. FTIR spectra of pure PSF, PSF/MMt, PSF/MMt/G, PSF/MMt/GO, PSF/MMt/CNTs, and $\mathrm{PSF} / \mathrm{MMt} / \mathrm{CNTOxi}$.

\subsubsection{X-ray Diffraction (XRD)}

$X R D$ was utilized to determine the dispersion of the organic and inorganic nanofillers within the PSF matrix. Figure 2 shows the XRD patterns of pristine PSF and its hybrid nanocomposites. The XRD pattern of PSF showed a broad peak at $17^{\circ}$ owing to the amorphous structure of the PSF chains. Various studies have indicated that GO exhibits a diffraction peak at $10.8^{\circ}$, whereas G, CNTs, and CNTOxi exhibit diffraction peaks at $26^{\circ}$ [28,42]. The modified MMt exhibits a diffraction peak at 35.9 $[43]$. From Figure 2, the peaks of MMt that had a higher alkyl ammonium chain as a surfactant disappeared when mixed with PSF and G, GO, CNTs, or CNTOxi. In addition, the G, GO, CNTs, and CNTOxi with PSF had peaks in the same 2 theta values, which indicates no structural distortion of these fillers due to mixing with PSF. Furthermore, changes in the intensity of diffraction peaks indicate variations in the crystallinity of composite materials. As shown in Figure 2, the diffraction peaks in the XRD patterns of PSF/MMt/CNTs and PSF/MMt/CNTOxi had low intensities, indicating a decrease in crystallinity, which suggests that the nanomaterials had good compatibility and were well dispersed within PSF. Conversely, the diffraction peak for G in PSF/MMt/G was sharp. In the PSF/MMT/GO sample, the peak of GO at $10.8^{\circ}$ was not observed because it was overlapped by the broad peak of PSF. 


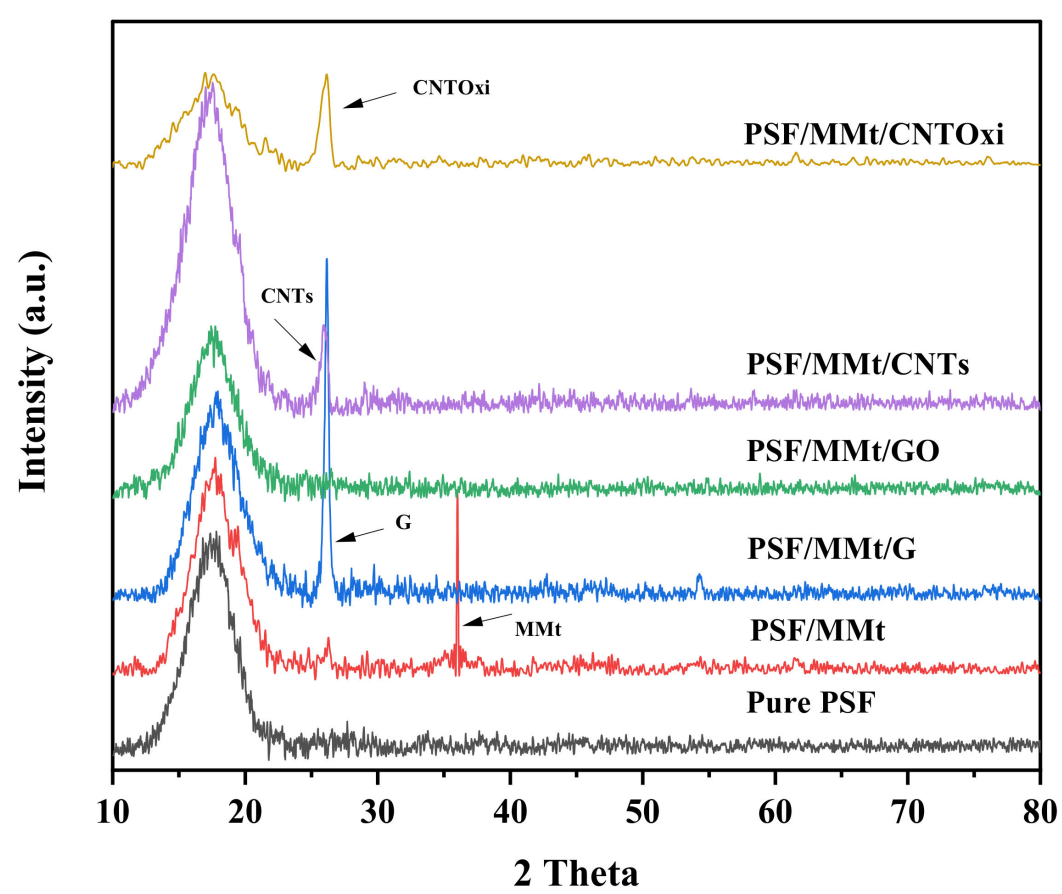

Figure 2. XRD patterns of pure PSF, PSF/MMt, PSF/MMt/G, PSF/MMt/GO, PSF/MMt/CNTs, and $\mathrm{PSF} / \mathrm{MMt} / \mathrm{CNTOxi}$.

\subsubsection{Scanning Electron Microscopy (SEM)}

As good dispersion of the nanofillers within PSF is essential to maintain the polymer matrix properties, the morphologies of the hybrid nanocomposite membranes were examined using SEM. Figure 3 shows representative SEM images of the top surfaces (Figure $3 \mathrm{a}-\mathrm{f}$ ) and cross-sections (Figure $3 \mathrm{~g}-\mathrm{l}$ ) of the membranes. The pristine PSF membrane possessed a smooth and homogenous surface (Figure 3a). The addition of MMt to PSF led to a random and homogeneous distribution of MMt nanoparticles over the entire surface (Figure 3b). As shown in Figure $3 c-f$, the surface became much rougher with the addition of the carbon-based nanofillers, which were well dispersed in the polymer matrix without any serious agglomeration. The nanofillers appeared pale on the surface owing to the good compatibility between PSF, MMt, and the carbon nanomaterials. Moreover, no cracks were observed on the surface, indicating that the membranes did not become brittle upon the addition of nanofillers. The cross-sectional images of the membranes reveal an asymmetric sponge-like structure (Figure $3 g-1$ ). All membranes exhibited a dense skin layer, and the boundaries between the nanofillers and the PSF matrix were not defined, suggesting strong interfacial adhesion. These results confirm good compatibility between the nanofillers and PSF $[1,15,29,32,44]$.

\subsubsection{Thermogravimetric Analysis (TGA)}

The thermal stabilities of pristine PSF and hybrid nanocomposites were examined by TGA at a rate of $10{ }^{\circ} \mathrm{C} / \mathrm{min}$ under a nitrogen atmosphere (Figure 4). The TGA curves of all the membranes showed one main degradation step over the temperature range of $70-750{ }^{\circ} \mathrm{C}$, except PSF/MMt started degradation from $35^{\circ} \mathrm{C}$. The degradation before $230^{\circ} \mathrm{C}$ was attributed to the removal of water or other impurities; the decomposition step after 230 to $750{ }^{\circ} \mathrm{C}$ for pristine PSF and the nanocomposites was due to PSF and nanofillers degradation. 

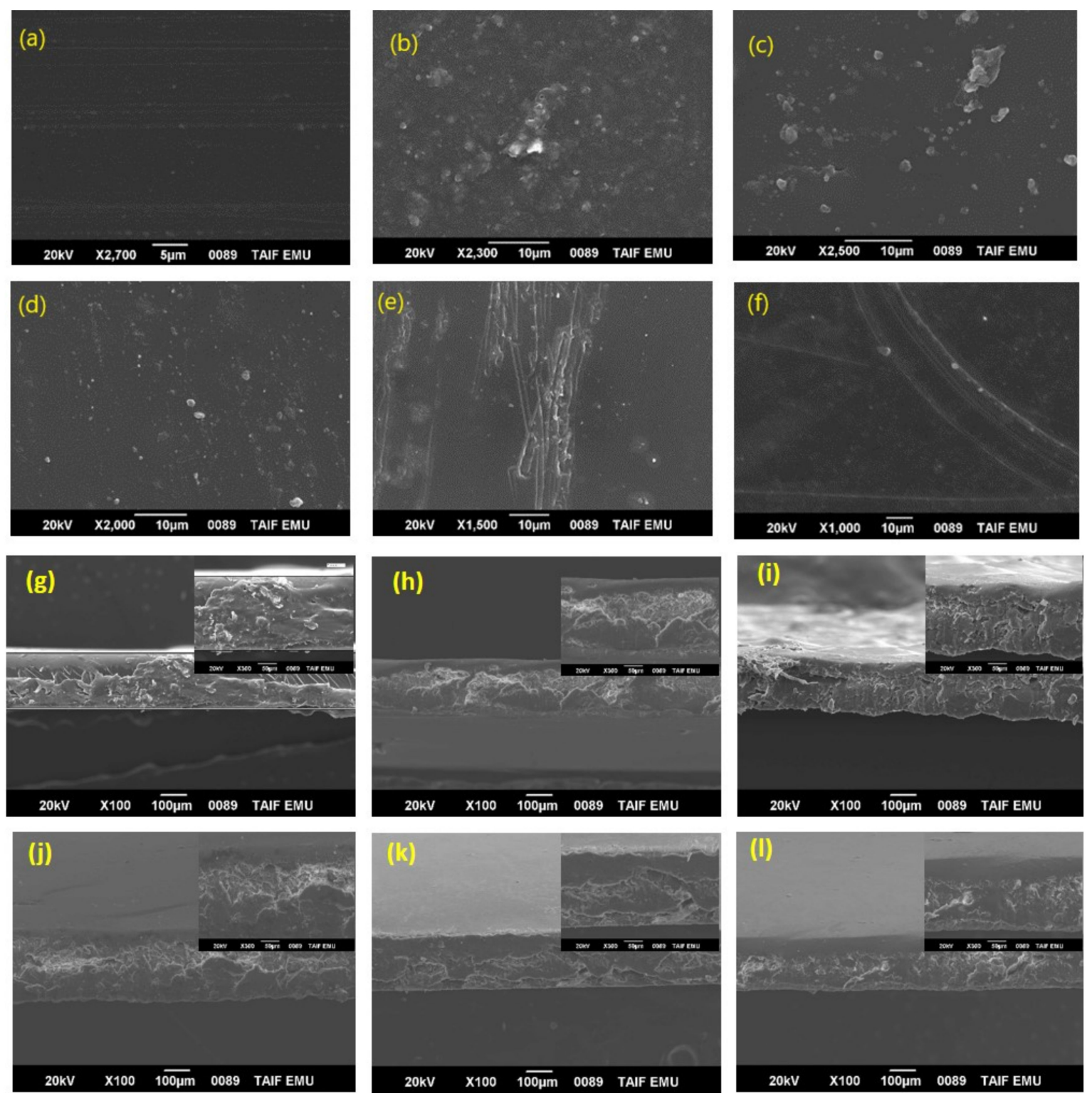

Figure 3. SEM images (top-surface and cross-section) of pure PSF (a,g), PSF/MMt (b,h), PSF/MMt/G (c,i), PSF/MMt/GO $(\mathbf{d}, \mathbf{j}), \mathrm{PSF} / \mathrm{MMt} / \mathrm{CNTs}(\mathbf{e}, \mathbf{k})$, and PSF/MMt/CNTOxi (f,l).

Generally, the thermal stabilities of the nanocomposite membranes were higher than that of the pristine PSF membrane. For PSF/MMt, the addition of MMt did not improve the thermal stability of the membrane, primarily because the organically modified clay contained surfactants with low thermal stability [19]. In the hybrid nanocomposite membranes, the presence of MMt and the carbon nanomaterials improved the thermal stability of PSF. Particularly, PSF/MMt/CNTs demonstrated more thermal stabilization compared to other nanocomposite membranes. Table 2 lists some of the important thermogravimetric data. Degradation temperatures, $\mathrm{T} 10$ and T50, were enhanced by $150{ }^{\circ} \mathrm{C}$ due to the incorporation of nanofiller in pure PSF. More importantly, the solid residue left at $750{ }^{\circ} \mathrm{C}$ are the main criteria indicating the thermal stability of the nanocomposites. The higher these values are, the higher is the thermal stability. 


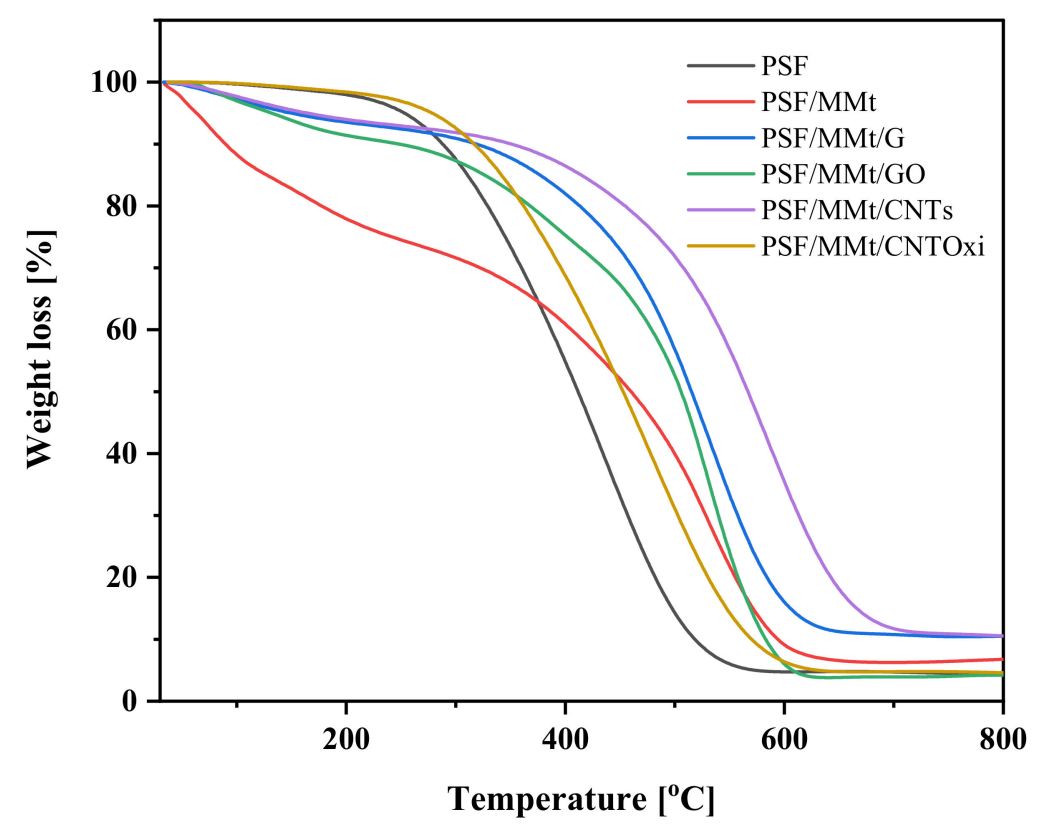

Figure 4. TGA curves of pure PSF, PSF/MMt, PSF/MMt/G, PSF/MMt/GO, PSF/MMt/CNTs, and PSF/MMt/CNTOxi.

Table 2. Thermogravimetric data for the investigated samples.

\begin{tabular}{cccc}
\hline & $\mathbf{T}_{\mathbf{1 0}}\left({ }^{\circ} \mathbf{C}\right)$ & $\mathbf{T}_{\mathbf{5 0}}\left({ }^{\circ} \mathbf{C}\right)$ & Residue at $\mathbf{7 5 0}\left({ }^{\circ} \mathbf{C}\right) \mathbf{\%}$ \\
\hline Pure PSF & 288 & 411 & 4.7 \\
PSF/MMt & 90 & 460 & 6.6 \\
PSF/MMt/G & 316 & 515 & 10.8 \\
PSF/MMt/GO & 246 & 505 & 4.7 \\
PSF/MMt/CNTs & 350 & 566 & 10.8 \\
PSF/MMt/CNTOxi & 316 & 452 & 4.7 \\
\hline
\end{tabular}

\subsubsection{Mechanical Properties}

The mechanical performance of polymer nanocomposites depends on various factors such as the dispersion state, the nanofiller characteristics, and interfacial interactions between the matrix and the filler. The mechanical stabilities of pristine PSF, PSF/MMt, $\mathrm{PSF} / \mathrm{MMt} / \mathrm{G}, \mathrm{PSF} / \mathrm{MMt} / \mathrm{GO}, \mathrm{PSF} / \mathrm{MMt} / \mathrm{CNTs}$, and PSF/MMt/CNTOxi were evaluated at room temperature in the dry state. The flexural modulus of elasticity and tensile strain at break values of the membranes are listed in Table 3, whereas the tensile properties and impact strength are listed in Table 4.

Table 3. Flexural modulus of elasticity in tension and tensile strain at break of PSF and its related carbon-based nanocomposites.

\begin{tabular}{|c|c|c|c|c|c|}
\hline \multirow[b]{2}{*}{ Code } & \multicolumn{3}{|c|}{ Flexural Properties } & \multirow[b]{2}{*}{$\begin{array}{l}\text { Modulus of Elasticity in } \\
\text { Tension (MPa) }\end{array}$} & \multirow[b]{2}{*}{$\begin{array}{c}\text { Tensile Strain at } \\
\text { Break }(\%)\end{array}$} \\
\hline & $\begin{array}{l}\text { Strength } \\
\text { (MPa) }\end{array}$ & $\begin{array}{l}\text { Modulus } \\
\text { (GPa) }\end{array}$ & $\begin{array}{l}\text { Toughness } \\
\left(\mathbf{k J} / \mathrm{m}^{2}\right)\end{array}$ & & \\
\hline PSF & $3.86( \pm 0.61)$ & $96.68( \pm 0.28)$ & $3.54( \pm 0.65)$ & $73.15( \pm 1.6)$ & $30.22( \pm 0.54)$ \\
\hline PSF/MMt & $4.47( \pm 0.98)$ & $132.61( \pm 1.22)$ & $4.03( \pm 0.23)$ & $70.08( \pm 1.2)$ & $29.43( \pm 0.27)$ \\
\hline $\mathrm{PSF} / \mathrm{MMt} / \mathrm{G}$ & $5.83( \pm 0.22)$ & $134.92( \pm 1.07)$ & $5.54( \pm 0.12)$ & $54.21( \pm 1.5)$ & $18.65( \pm 0.71)$ \\
\hline PSF/MMt/GO & $6.03( \pm 0.28)$ & $139.32( \pm 1.02)$ & $5.88( \pm 0.82)$ & $58.27( \pm 1.7)$ & $14.03( \pm 0.56)$ \\
\hline $\mathrm{PSF} / \mathrm{MMt} / \mathrm{CNTs}$ & $5.46( \pm 0.12)$ & $140.67( \pm 1.43)$ & $4.98( \pm 0.75)$ & $52.34( \pm 1.3)$ & $16.05( \pm 0.32)$ \\
\hline PSF/MMt/CNTOxi & $6.84( \pm 0.16)$ & $143.42( \pm 0.99)$ & $5.15( \pm 0.41)$ & $60.22( \pm 1.4)$ & $12.94( \pm 0.19)$ \\
\hline
\end{tabular}


Table 4. Tensile properties and impact strength of PSF and its related carbon-based nanocomposites.

\begin{tabular}{|c|c|c|c|c|}
\hline \multirow[b]{2}{*}{ Code } & \multicolumn{3}{|c|}{ Tensile Properties } & \multirow{2}{*}{$\begin{array}{c}\text { Impact Strength } \\
\left(\mathrm{KJ} / \mathrm{m}^{2}\right)\end{array}$} \\
\hline & $\begin{array}{l}\text { Strength } \\
\text { (MPa) }\end{array}$ & $\begin{array}{l}\text { Modulus } \\
\text { (GPa) }\end{array}$ & $\begin{array}{l}\text { Toughness } \\
\left(\mathbf{k J} / \mathrm{m}^{2}\right)\end{array}$ & \\
\hline PSF & $3.96( \pm 0.13)$ & $99.26( \pm 0.87)$ & $6.43( \pm 1.94)$ & $1.25( \pm 0.86)$ \\
\hline PSF/MMt & $4.32( \pm 0.52)$ & $114.57( \pm 1.08)$ & $7.28( \pm 0.76)$ & $1.45( \pm 1.18)$ \\
\hline $\mathrm{PSF} / \mathrm{MMt} / \mathrm{G}$ & $5.68( \pm 0.45)$ & $128.28( \pm 1.25)$ & $7.77( \pm 0.58)$ & $1.60( \pm 1.04)$ \\
\hline PSF/MMt/GO & $6.07( \pm 0.86)$ & $134.44( \pm 1.13)$ & $9.34( \pm 1.11)$ & $1.69( \pm 0.82)$ \\
\hline $\mathrm{PSF} / \mathrm{MMt} / \mathrm{CNTs}$ & $6.82( \pm 0.82)$ & $139.92( \pm 1.05)$ & $7.08( \pm 1.26)$ & $1.62( \pm 1.07)$ \\
\hline PSF/MMt/CNTOxi & $7.54( \pm 0.91)$ & $133.51( \pm 1.55)$ & $8.40( \pm 1.31)$ & $1.76( \pm 0.99)$ \\
\hline
\end{tabular}

Various studies have reported that the addition of clay enhances the mechanical properties of membranes because of an increased sponge-like structure and smaller voids. However, membranes synthesized with clay and PEG have poor mechanical properties owing to the presence of pores, reduced stiffness, and tensile strength [23]. Other studies have found that the addition of G or CNTs to PSF can also improve the mechanical properties. In this study, the hybrid membranes exhibited excellent mechanical properties because of the presence of both MMt and a carbon nanofiller [30,36].

The hybrid nanocomposite membranes exhibited better flexural properties (Table 3) and tensile properties (Table 4) than the pristine PSF and PSF/MMt membranes. This enhancement was attributed to the excellent dispersion of the binary nanofillers in the PSF matrix and a strong interface resulting from good interactions between the nanoparticles and the polymer chains $[3,28]$. However, the tensile strain at break values was decreased for the hybrid membranes (Table 3), which indicates that the hybrid membranes are more brittle, likely because the binary fillers hinder the sliding of PSF chains to a greater extent than a single filler. Furthermore, PSF/MMt/GO showed remarkably improved flexural and tensile properties as compared to PSF/MMt/G. Similarly, $\mathrm{PSF} / \mathrm{MMt} / \mathrm{CNTOxi}$ exhibited greater mechanical strength than PSF/MMt/CNTs. This effect was attributed to the improved interfacial compatibility owing to hydrogen bonding between the nanomaterials and the PSF matrix.

\subsection{Adsorption Performance of Hybrid Nanocomposite Membranes}

PSF has been extensively used to remove diverse environmental pollutants. Therefore, the hybrid nanocomposite membranes were used to extract toxic $\mathrm{Hg}$ (II) from aqueous solutions as surface-selective adsorbents. All the nanocomposite membranes yielded significantly higher adsorption efficiencies than pristine PSF and PSF/MMt. As PSF/MMt/CNTOxi and PSF/MMt/GO exhibited the highest adsorption efficiencies among the investigated membranes, their adsorption performance was investigated in detail. The distribution coefficient $\left(K_{d}\right)$ for the selectivity of the membranes toward different metal ions was calculated using the following equation:

$$
K_{d}=\frac{\left(C_{o}-C_{e}\right)}{C_{e}} \times \frac{V}{M}
$$

where $C_{o}$ and $C_{e}$ are the initial and final concentrations before and after filtration, respectively, $m$ is the weight of the adsorbent $(\mathrm{g})$, and $V$ is the volume $(\mathrm{mL})$. Table 5 contains the distribution coefficient values for all the metal ions in this study. 
Table 5. Surface selectivity study on the adsorption of pure PSF, PSF/MMt, PSF/MMt/G, $\mathrm{PSF} / \mathrm{MMt} / \mathrm{CNTs}$, PSF/MMt/GO, and PSF/MMt/CNTOxi toward different metal ions at $25^{\circ} \mathrm{C}$.

\begin{tabular}{cccc}
\hline Material & Metal Ions & $q_{\boldsymbol{e}}(\mathbf{m g} / \mathbf{g})$ & $\boldsymbol{K}_{\boldsymbol{d}}(\mathbf{m L} / \mathbf{g})$ \\
\hline PSF/MMt/CNTOxi & $\mathrm{Hg}^{+2}$ & 2.08 & $61,357.25$ \\
& $\mathrm{Ni}^{+2}$ & 0.11 & 49.57 \\
& $\mathrm{Fe}^{+3}$ & 0.34 & 167.82 \\
& $\mathrm{Cr}^{+3}$ & 0.23 & 32.41 \\
& $\mathrm{Y}^{+3}$ & 0.37 & 45.67 \\
& $\mathrm{Al}^{+3}$ & 0.46 & 147.69 \\
& $\mathrm{~Pb}^{+2}$ & 0.59 & 186.43 \\
& $\mathrm{Zn}^{+2}$ & 0.14 & 55.67 \\
& $\mathrm{Co}^{+2}$ & 0.29 & 42.83 \\
& $\mathrm{Sr}^{+2}$ & 0.04 & 12.87 \\
\hline PSF/MMt/G & $\mathrm{Hg}^{+2}$ & 1.12 & 1829.46 \\
PSF/MMt/GO & $\mathrm{Hg}^{+2}$ & 1.98 & $56,947.72$ \\
& $\mathrm{Hg}^{+2}$ & 1.19 & 1958.31 \\
\hline P/MMt & $\mathrm{Hg}^{+2}$ & 0.35 & 77.82 \\
Pure PSF & $\mathrm{Hg}^{+2}$ & 0.17 & 62.17 \\
\hline
\end{tabular}

As shown in Table 5, among the investigated metal ions, PSF/MMt/CNTOxi had the higher distribution coefficient value for $\mathrm{Hg}(\mathrm{II})(61,357.25 \mathrm{~mL} / \mathrm{g})$. This result indicates that $\mathrm{PSF} / \mathrm{MMt} / \mathrm{CNTOxi}$ is selective toward $\mathrm{Hg}(\mathrm{II})$.

\subsubsection{Effect of $\mathrm{pH}$}

Owing to the effect of $\mathrm{H}^{+}$ions on the ionization degree and adsorbate species, the $\mathrm{pH}$ plays a vital role in the extraction of metal ions from aqueous media [7]. Therefore, the effect of $\mathrm{pH}$ on the adsorption of $\mathrm{Hg}$ (II) by PSF/MMt/CNTOxi and PSF/MMt/GO was investigated. Using $2 \mathrm{mg} / \mathrm{L} \mathrm{Hg}(\mathrm{II})$, the solution $\mathrm{pH}$ was varied from 1 to 11. Each standard solution was mixed with $20 \mathrm{mg}$ of PSF/MMt/CNTOxi or PSF/MMt/GO at $25{ }^{\circ} \mathrm{C}$. As shown in Figure 5 shows, the solution $\mathrm{pH}$ had a remarkable effect on the extraction of heavy metals process, with the extraction percentage of $\mathrm{Hg}$ (II) first increasing and then decreasing as the $\mathrm{pH}$ value increased.

PSF/MMt/CNTOxi and PSF/MMt/GO showed the highest $\mathrm{Hg}$ (II) extraction percentages at $\mathrm{pH} 2.0$ (98\% and 95\%, respectively), which indicates that the selectivity toward $\mathrm{Hg}$ (II) was maximized at this $\mathrm{pH}$ value. This enhanced $\mathrm{Hg}$ (II) extraction performance can be explained by electrostatic interactions between the protonated carbonyl groups of $\mathrm{PSF} / \mathrm{MMt} / \mathrm{CNTOxi}$ or PSF/MMt/GO and the negatively charged species $\mathrm{HgCl}_{4}{ }^{-}$at $\mathrm{pH}$ 2.0, which is the main form of $\mathrm{Hg}$ (II) ion in $\mathrm{HCl}$ solution. Thus, $\mathrm{Hg}$ (II) was selectively extracted from the solution. Based on these results, the optimum $\mathrm{pH}$ value of 2.0 was used in subsequent investigations of the $\mathrm{Hg}$ (II) uptake capacities of PSF/MMt/CNTOxi and $\mathrm{PSF} / \mathrm{MMt} / \mathrm{GO}$ under static conditions.

\subsubsection{Determination of Adsorption Capacity}

The $\mathrm{Hg}(\mathrm{II})$ uptake capacity was investigated at $\mathrm{pH} 2.0$ using different amounts of $\mathrm{Hg}$ (II) mixed with $20 \mathrm{mg}$ of PSF/MMt/CNTOxi or PSF/MMt/GO using a batch method. From the obtained adsorption isotherms, the adsorption capacities of PSF/MMt/CNTOxi and PSF/MMt/GO for $\mathrm{Hg}(\mathrm{II})$ were found to be 151.36 and $144.89 \mathrm{mg} / \mathrm{g}$, respectively, at $150 \mathrm{mg} / \mathrm{L}$ of $\mathrm{Hg}(\mathrm{II})$ concentration (Figure 6). 


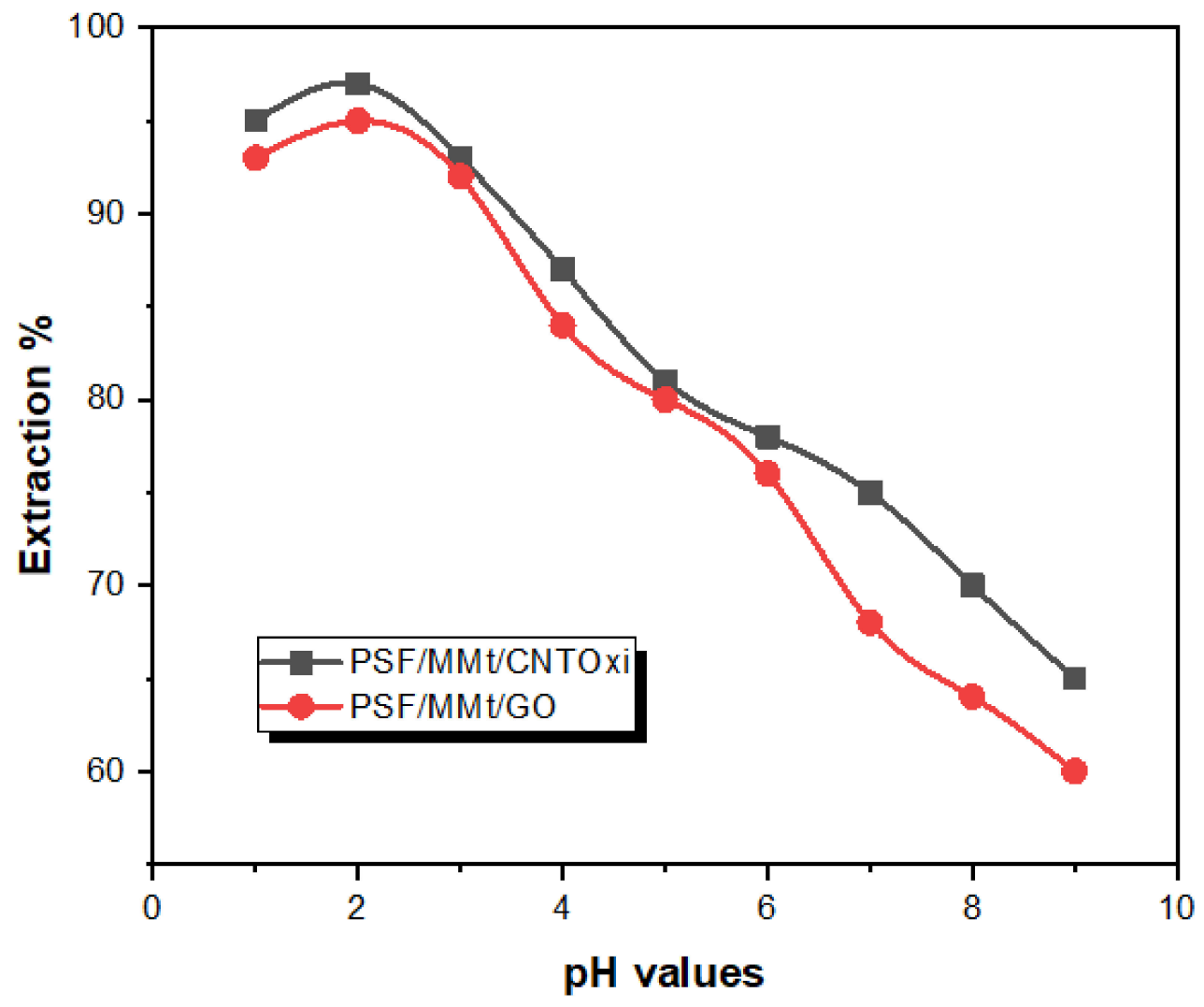

Figure 5. The $\mathrm{pH}$ effect on the adsorption of $\mathrm{Hg}^{+2}$ ion $(2 \mathrm{mg} / \mathrm{L})$ on $25 \mathrm{mg}$ of PSF/MMt/GO and PSF/MMt/CNTOxi respectively at $25^{\circ} \mathrm{C}$.

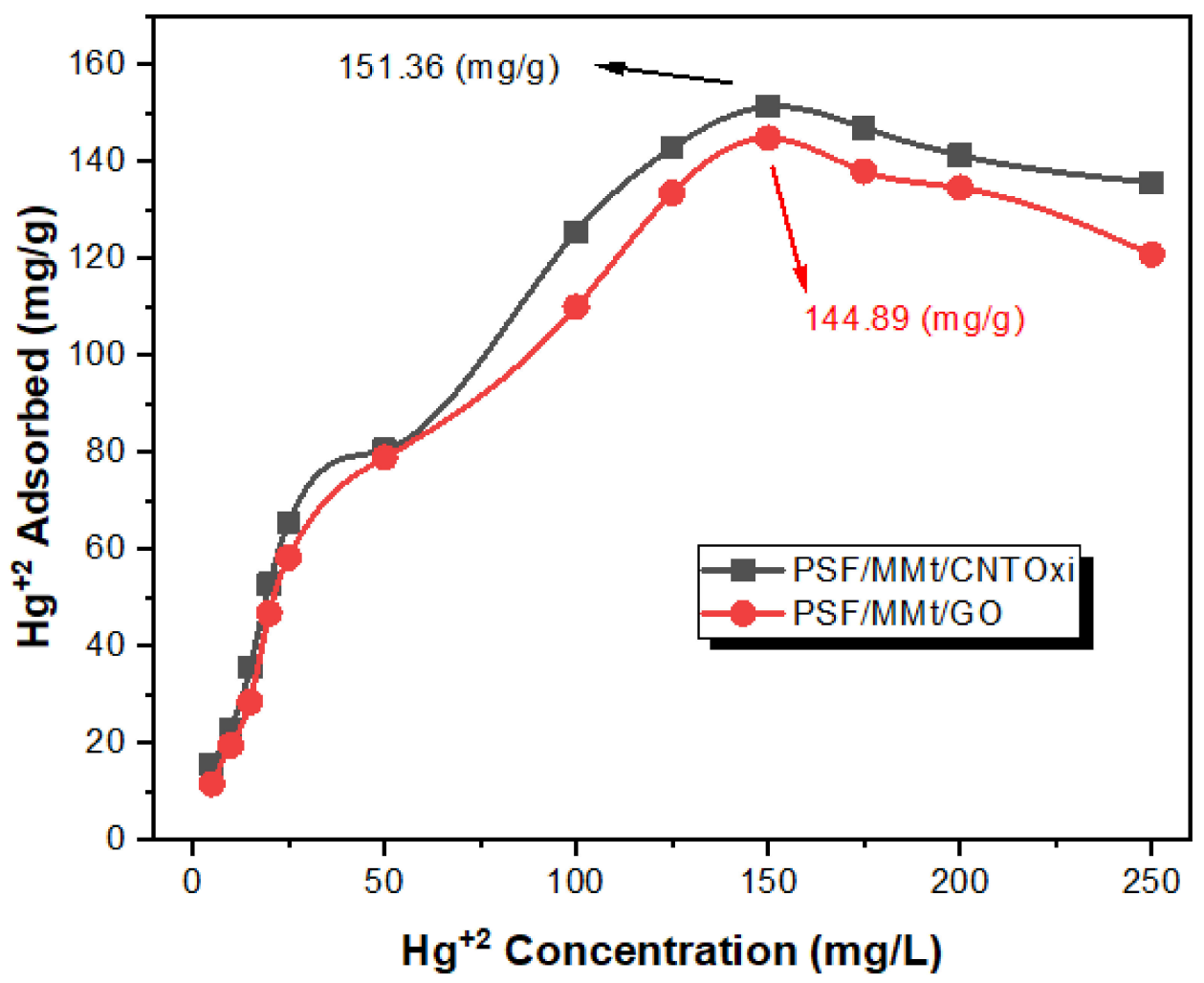

Figure 6. The adsorption profile of $\mathrm{Hg}^{+2}$ ion on $25 \mathrm{mg}$ of PSF/MMt/GO and PSF/MMt/CNTOxi, respectively, in relation to the concentration at $\mathrm{pH} 2.0$ and $25^{\circ} \mathrm{C}$. 
Figure 6 also shows that there was a small decrease in the $\mathrm{Hg}$ (II) uptake capacities of $\mathrm{PSF} / \mathrm{MMt} / \mathrm{CNTOxi}$ and PSF/MMt/GO after saturation, at higher than $150 \mathrm{mg} / \mathrm{L}$. This behavior was attributed to the binding sites of PSF/MMt/CNTOxi or PSF/MMt/GO being saturated with $\mathrm{HgCl}_{4}{ }^{-}$species, especially at $250 \mathrm{mg} / \mathrm{L}$, with the highest concentration of $\mathrm{Hg}(\mathrm{II})$. The stabilities of PSF/MMt/CNTOxi and PSF/MMt/GO were investigated over three cycles. The membranes exhibited little change in adsorption capacity, indicating their excellent stability, and thus could be reused with high efficiency [45].

\subsubsection{Adsorption Isotherm Models}

Adsorption isotherm models can be described by Langmuir adsorption models. The experimental data were fitted well by the Langmuir equation to describe adsorption isotherm models, as illustrated in Figure 7.

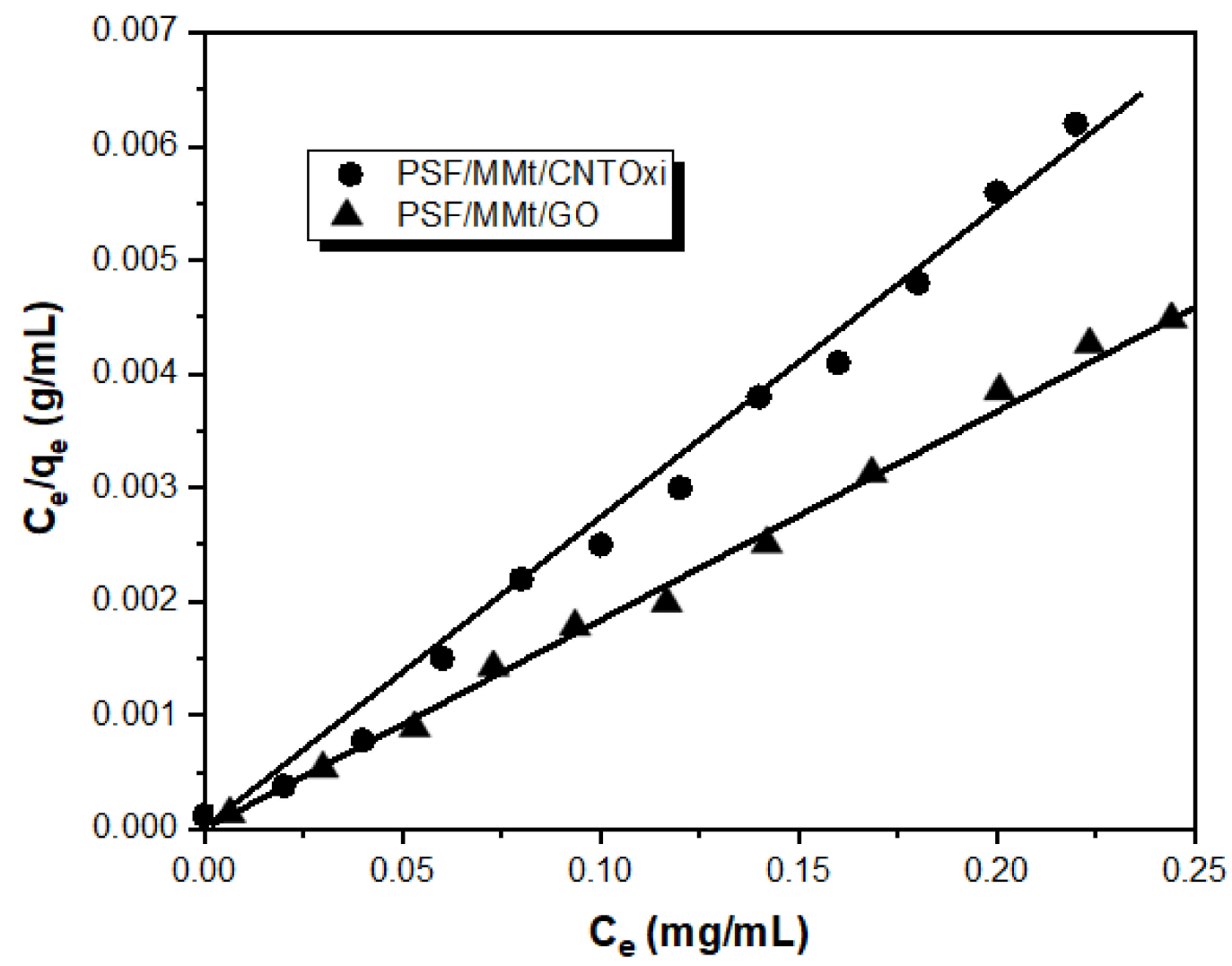

Figure 7. Langmuir adsorption isotherm model of $\mathrm{Hg}^{+2}$ ion adsorption on $25 \mathrm{mg}$ of PSF/MMt/GO and PSF/MMt/CNTOxi respectively, at $\mathrm{pH} 2.0$ and $25^{\circ} \mathrm{C}$. Adsorption experiments were obtained at different concentrations $(0-250 \mathrm{mg} / \mathrm{L})$ of $\mathrm{Hg}^{+2}$ under static conditions.

According to the Langmuir adsorption isotherm, the uniformity of non-interacting surface area sites was measured by the mathematical expression of this model:

$$
C_{e} / q_{e}=\left(C_{e} / Q_{o}\right)+1 / Q_{o} b
$$

where $C_{e}$ is the concentration and $q_{e}$ is the amount of metal ions in solution at equilibrium, respectively. $Q_{o}$ and $b$ are Langmuir constants for the adsorbent, they can be calculated from a linear plot of $C_{e} / q_{e}$ against $C_{e}$, which has a slope and intercept equal to $1 / Q_{o}$ and $1 / Q_{0} b$, respectively. Moreover, an equilibrium parameter, $R_{L}$, is from the essential characteristics of the Langmuir adsorption isotherm model, which is defined as follows:

$$
R_{L}=1 /\left(1+b C_{o}\right)
$$


where $b$ is the Langmuir constant, which indicates the adsorption nature and different isotherm shapes, and $C_{o}$ is the initial concentration of $\mathrm{Hg}(\mathrm{II})$. The value of $R_{L}$ describes the adsorption isotherm nature, and values of $0<R_{L}<$ represent favorable adsorption. A linear plot was obtained from the Langmuir isotherm equation based on least-squares fitting, confirming the validity of the Langmuir adsorption isotherm model for the adsorption process, as shown in Figure 7. The above results indicate that adsorbed $\mathrm{Hg}$ (II) forms a monolayer on the homogeneous PSF/MMt/CNTOxi surface, which is a monolayer during the adsorption process. The Langmuir constants $Q_{0}$ and $b$ were calculated as $149.36 \mathrm{mg} / \mathrm{g}$ and $0.36 \mathrm{~L} / \mathrm{mg}$, respectively, for PSF/MMt/CNTOxi, and $142.48 \mathrm{mg} / \mathrm{g}$ and $0.28 \mathrm{~L} / \mathrm{mg}$, respectively, for PSF/MMt/GO (Table 6).

Table 6. Parameters of Langmuir isotherm constants of PSF/MMt/CNTOxi and PSF/MMt/GO surfaces respectively against the adsorption of $\mathrm{Hg}^{+2}$, at $\mathrm{pH} 2.0$ and $25^{\circ} \mathrm{C}(\mathrm{N}=3)$.

\begin{tabular}{ccccc}
\hline Material & $Q_{o}(\mathbf{m g} / \mathbf{g})$ & $\boldsymbol{b}(\mathrm{L} / \mathbf{m g})$ & $\boldsymbol{R}^{\mathbf{2}}$ & $\boldsymbol{R}_{\boldsymbol{L}}$ \\
\hline PSF/MMt/CNTOxi & 149.36 & 0.36 & 0.992 & 0.04 \\
PSF/MMt/GO & 142.48 & 0.28 & 0.985 & 0.02 \\
\hline
\end{tabular}

Table 6 shows the data could be satisfactorily fitted with the Langmuir model. The correlation coefficient $\left(R_{2}\right)$ obtained from the Langmuir model was 0.992 for the adsorption of $\mathrm{Hg}$ (II) on PSF/MMt/CNTOxi and 0.985 for PSF/MMt/GO. The $R_{L}$ value for $\mathrm{Hg}$ (II) adsorption on PSF/MMt/CNTOxi was 0.04 , which indicated a highly favorable adsorption process. In addition, the $\mathrm{Hg}(\mathrm{II})$ adsorption capacity $(149.36 \mathrm{mg} / \mathrm{g})$ was in good agreement with that $(151.36 \mathrm{mg} / \mathrm{g})$ obtained experimentally from the adsorption isotherm.

\section{Conclusions}

In the present study, G, GO, CNTs, or CNTOxi-incorporated PSF/MMt nanocomposite adsorptive membranes were fabricated for the removal of heavy metal ions from aqueous media. FTIR spectroscopy, XRD, and SEM indicated good compatibility and excellent dispersibility of the organoclay (MMt) and carbon nanomaterials (G, GO, CNTs, or CNTOxi) in the PSF matrix. The thermal stabilities of the hybrid nanocomposite membranes were higher than that of pristine PSF and PSF/MMt. Moreover, all the hybrid nanocomposites (especially PSF/MMt/CNTOxi and PSF/MMt/GO) showed enhanced mechanical properties as compared to pristine PSF, proving the formation of a strong interface, which is required for efficient load transfer from the PSF matrix to the binary filler. Furthermore, an investigation of the adsorption performance of the membranes for various metal ions revealed that PSF/MMt/CNTOxi and PSF/MMt/GO had the highest adsorption efficiencies. The adsorption capacities of PSF/MMt/CNTOxi and PSF/MMt/GO for $\mathrm{Hg}$ (II) at $\mathrm{pH} 2$ were 151.36 and $144.89 \mathrm{mg} / \mathrm{g}$, respectively, and the adsorption isotherms were in agreement with the Langmuir model. In conclusion, these results confirmed that the PSF membrane by mixing with modified MMt and carbon materials can be a promising material for future industrial applications.

Funding: This research was funded by Deanship of the Scientific Research, Taif University, grant number 1-441-16.

Institutional Review Board Statement: Not applicable.

Informed Consent Statement: Not applicable.

Data Availability Statement: The data presented in this study are available on request from the author.

Acknowledgments: The author thanks the financial support from Deanship of the Scientific Research under Project number (1-441-16), Taif University, Taif, Saudi Arabia.

Conflicts of Interest: The author declares no conflict of interest. 


\section{References}

1. Wang, H.; Lu, X.; Lu, X.; Wang, Z.; Ma, J.; Wang, P. Improved surface hydrophilicity and antifouling property of polysulfone ultrafiltration membrane with poly(ethylene glycol) methyl ether methacrylate grafted graphene oxide nanofillers. Appl. Surf. Sci. 2017, 425, 603-613. [CrossRef]

2. Kang, Y.; Obaid, M.; Jang, J.; Ham, M.-H.; Kim, I.S. Novel sulfonated graphene oxide incorporated polysulfone nanocomposite membranes for enhanced-performance in ultrafiltration process. Chemosphere 2018, 207, 581-589. [CrossRef] [PubMed]

3. Zheng, N.; Sun, W.; Liu, H.-Y.; Huang, Y.; Gao, J.; Mai, Y.-W. Effects of carboxylated carbon nanotubes on the phase separation behaviour and fracture-mechanical properties of an epoxy/polysulfone blend. Compos. Sci. Technol. 2018, 159, 180-188. [CrossRef]

4. Hwang, T.; Oh, J.-S.; Yim, W.; Nam, J.-D.; Bae, C.; Kim, H.-I.; Kim, K. Ultrafiltration using graphene oxide surface-embedded polysulfone membranes. Sep. Purif. Technol. 2016, 166, 41-47. [CrossRef]

5. Esfahani, M.R.; Tyler, J.; Stretz, H.; Wells, M.J. Effects of a dual nanofiller, nano- $\mathrm{TiO}_{2}$ and MWCNT, for polysulfone-based nanocomposite membranes for water purification. Desalination 2015, 372, 47-56. [CrossRef]

6. Modi, A.; Bellare, J. Efficiently improved oil/water separation using high flux and superior antifouling polysulfone hollow fiber membranes modified with functionalized carbon nanotubes/graphene oxide nanohybrid. J. Environ. Chem. Eng. 2019, 7, 102944. [CrossRef]

7. Al-Ghamdi, Y.O.; Alamry, K.A.; Hussein, M.A.; Marwani, H.M.; Asiri, A.M. Sulfone-modified chitosan as selective adsorbent for the extraction of toxic $\mathrm{Hg}$ (II) metal ions. Adsorpt. Sci. Technol. 2018, 37, 139-159. [CrossRef]

8. Bassyouni, M.; Abdel-Aziz, M.; Zoromba, M.S.; Abdel-Hamid, S.; Drioli, E. A review of polymeric nanocomposite membranes for water purification. J. Ind. Eng. Chem. 2019, 73, 19-46. [CrossRef]

9. Buruga, K.; Song, H.; Shang, J.; Bolan, N.; Jagannathan, T.K.; Kim, K.-H. A review on functional polymer-clay based nanocomposite membranes for treatment of water. J. Hazard. Mater. 2019, 379, 120584. [CrossRef] [PubMed]

10. Kochameshki, M.G.; Marjani, A.; Mahmoudian, M.; Farhadi, K. Grafting of diallyldimethylammonium chloride on graphene oxide by RAFT polymerization for modification of nanocomposite polysulfone membranes using in water treatment. Chem. Eng. J. 2017, 309, 206-221. [CrossRef]

11. Zambianchi, M.; Durso, M.; Liscio, A.; Treossi, E.; Bettini, C.; Capobianco, M.; Aluigi, A.; Kovtun, A.; Ruani, G.; Corticelli, F.; et al. Graphene oxide doped polysulfone membrane adsorbers for the removal of organic contaminants from water. Chem. Eng. J. 2017, 326, 130-140. [CrossRef]

12. Serbanescu, O.; Voicu, S.; Thakur, V. Polysulfone functionalized membranes: Properties and challenges. Mater. Today Chem. 2020, 17, 100302. [CrossRef]

13. Mocanu, A.; Rusen, E.; Diacon, A.; Isopencu, G.; Mustățea, G.; Şomoghi, R.; Dinescu, A. Antimicrobial properties of polysulfone membranes modified with carbon nanofibers and silver nanoparticles. Mater. Chem. Phys. 2018, 223, 39-45. [CrossRef]

14. Sanusi, O.M.; Benelfellah, A.; Hocine, N.A. Clays and carbon nanotubes as hybrid nanofillers in thermoplastic-based nanocomposites-A review. Appl. Clay Sci. 2019, 185, 105408. [CrossRef]

15. $\mathrm{Wu}, \mathrm{H}$.; Tang, B.; $\mathrm{Wu}, \mathrm{P}$. Development of novel $\mathrm{SiO}_{2}-\mathrm{GO}$ nanohybrid/polysulfone membrane with enhanced performance. J. Membr. Sci. 2014, 451, 94-102. [CrossRef]

16. Chai, P.; Mahmoudi, E.; Teow, Y.; Mohammad, A. Preparation of novel polysulfone- $\mathrm{Fe}_{3} \mathrm{O}_{4} / \mathrm{GO}$ mixed-matrix membrane for humic acid rejection. J. Water Process. Eng. 2017, 15, 83-88. [CrossRef]

17. Huang, L.; Zhao, S.; Wang, Z.; Wu, J.; Wang, J.; Wang, S. In situ immobilization of silver nanoparticles for improving permeability, antifouling and anti-bacterial properties of ultrafiltration membrane. J. Membr. Sci. 2016, 499, 269-281. [CrossRef]

18. Alsohaimi, I.H.; Kumar, M.; Algamdi, M.S.; Khan, M.A.; Nolan, K.; Lawler, J. Antifouling hybrid ultrafiltration membranes with high selectivity fabricated from polysulfone and sulfonic acid functionalized $\mathrm{TiO}_{2}$ nanotubes. Chem. Eng. J. 2017, 316, 573-583. [CrossRef]

19. Ammar, A.; Elzatahry, A.; Al-Maadeed, S.; Alenizi, A.M.; Huq, A.F.; Karim, A. Nanoclay compatibilization of phase separated polysulfone/polyimide films for oxygen barrier. Appl. Clay Sci. 2017, 137, 123-134. [CrossRef]

20. Daraei, P.; Ghaemi, N. Synergistic effect of Cloisite 15A and 30B nanofillers on the characteristics of nanocomposite polyethersulfone membrane. Appl. Clay Sci. 2019, 172, 96-105. [CrossRef]

21. Fu, S.-Y.; Sun, Z.; Huang, P.; Li, Y.-Q.; Hu, N. Some basic aspects of polymer nanocomposites: A critical review. Nano Mater. Sci. 2019, 1, 2-30. [CrossRef]

22. Mukhopadhyay, R.; Bhaduri, D.; Sarkar, B.; Rusmin, R.; Hou, D.; Khanam, R.; Sarkar, S.; Biswas, J.K.; Vithanage, M.; Bhatnagar, A.; et al. Clay-polymer nanocomposites: Progress and challenges for use in sustainable water treatment. J. Hazard. Mater. 2019, 383, 121125. [CrossRef]

23. Rodrigues, R.; Mierzwa, J.C.; Vecitis, C.D. Mixed matrix polysulfone/clay nanoparticles ultrafiltration membranes for water treatment. J. Water Process. Eng. 2019, 31, 100788. [CrossRef]

24. Singla, P.; Mehta, R.; Upadhyay, S.N. Clay Modification by the Use of Organic Cations. Green Sustain. Chem. 2012, 2, 21-25. [CrossRef]

25. Hu, B.; Miao, L.; Zhao, Y.; Lü, C. Azide-assisted crosslinked quaternized polysulfone with reduced graphene oxide for highly stable anion exchange membranes. J. Membr. Sci. 2017, 530, 84-94. [CrossRef]

26. Lei, T.; Xue, Q.; Chu, L.; Han, Z.; Sun, J.; Xia, F.; Zhang, Z.; Guo, Q. Excellent dielectric properties of polymer composites based on core-shell structured carbon/silica nanohybrid. Appl. Phys. Lett. 2013, 103, 12902. [CrossRef] 
27. Wang, J.; Jia, H.; Ding, L.; Zhu, L.; Dai, X.; Fei, X.; Li, F.; Gong, X. Utilization of silane functionalized carbon nanotubes-silica hybrids as novel reinforcing fillers for solution styrene butadiene rubber. Polym. Compos. 2013, 34, 690-696. [CrossRef]

28. Ionita, M.; Pandele, A.M.; Crica, L.; Pilan, L. Improving the thermal and mechanical properties of polysulfone by incorporation of graphene oxide. Compos. Part B Eng. 2014, 59, 133-139. [CrossRef]

29. Jiang, Y.; Zeng, Q.; Biswas, P.; Fortner, J.D. Graphene oxides as nanofillers in polysulfone ultrafiltration membranes: Shape matters. J. Membr. Sci. 2019, 581, 453-461. [CrossRef]

30. Peña-Bahamonde, J.; Miguel, V.S.; Baselga, J.; Fernández-Blázquez, J.P.; Gedler, G.; Ozisik, R.; Cabanelas, J.C. Effect of polysulfone brush functionalization on thermo-mechanical properties of melt extruded graphene/polysulfone nanocomposites. Carbon 2019, 151, 84-93. [CrossRef]

31. Jiang, Y.; Biswas, P.; Fortner, J.D. A review of recent developments in graphene-enabled membranes for water treatment. Environ. Sci. Water Res. Technol. 2016, 2, 915-922. [CrossRef]

32. Zhang, G.; Zhou, M.; Xu, Z.; Jiang, C.; Shen, C.; Meng, Q. Guanidyl-functionalized graphene/polysulfone mixed matrix ultrafiltration membrane with superior permselective, antifouling and antibacterial properties for water treatment. J. Colloid Interface Sci. 2019, 540, 295-305. [CrossRef]

33. Zunita, M. Graphene Oxide-Based Nanofiltration for Hg Removal from Wastewater: A Mini Review. Membranes 2021, 11, 269. [CrossRef]

34. Yin, J.; Zhu, G.; Deng, B. Multi-walled carbon nanotubes (MWNTs)/polysulfone (PSU) mixed matrix hollow fiber membranes for enhanced water treatment. J. Membr. Sci. 2013, 437, 237-248. [CrossRef]

35. Saleh, T.A.; Parthasarathy, P.; Irfan, M. Advanced functional polymer nanocomposites and their use in water ultra-purification. Trends Environ. Anal. Chem. 2019, 24. [CrossRef]

36. Xu, L.; He, J.; Yu, Y.; Chen, J.P. Effect of CNT content on physicochemical properties and performance of CNT composite polysulfone membranes. Chem. Eng. Res. Des. 2017, 121, 92-98. [CrossRef]

37. de Lannoy, C.-F.; Soyer, E.; Wiesner, M.R. Optimizing carbon nanotube-reinforced polysulfone ultrafiltration membranes through carboxylic acid functionalization. J. Membr. Sci. 2013, 447, 395-402. [CrossRef]

38. Kim, S.; Chen, L.; Johnson, J.K.; Marand, E. Polysulfone and functionalized carbon nanotube mixed matrix membranes for gas separation: Theory and experiment. J. Membr. Sci. 2007, 294, 147-158. [CrossRef]

39. Vatanpour, V.; Haghighat, N. Improvement of polyvinyl chloride nanofiltration membranes by incorporation of multiwalled carbon nanotubes modified with triethylenetetramine to use in treatment of dye wastewater. J. Environ. Manag. 2019, $242,90-97$. [CrossRef] [PubMed]

40. Goyanes, S.; Rubiolo, G.; Salazar, A.; Jimeno, A.; Corcuera, M.A.; Mondragon, I. Carboxylation treatment of multiwalled carbon nanotubes monitored by infrared and ultraviolet spectroscopies and scanning probe microscopy. Diam. Relat. Mater. 2007, 16, 412-417. [CrossRef]

41. Jyothi, M.; Nayak, V.; Padaki, M.; Balakrishna, R.G.; Soontarapa, K. Aminated polysulfone/TiO 2 composite membranes for an effective removal of Cr(VI). Chem. Eng. J. 2016, 283, 1494-1505. [CrossRef]

42. Alosaimi, A.; Hussein, M.; Abdelaal, M.; Elfaky, M.; Sobahi, T.; Abdel-Daiem, A. Polysulfone-based modified organoclay nanocomposites as a promising breast anticancer agent. Cogent Chem. 2017, 3, 1417672. [CrossRef]

43. Dlamini, D.S.; Li, J.; Mamba, B.B. Critical review of montmorillonite/polymer mixed-matrix filtration membranes: Possibilities and challenges. Appl. Clay Sci. 2018, 168, 21-30. [CrossRef]

44. Benally, C.; Li, M.; El-Din, M.G. The effect of carboxyl multiwalled carbon nanotubes content on the structure and performance of polysulfone membranes for oil sands process-affected water treatment. Sep. Purif. Technol. 2018, 199, 170-181. [CrossRef]

45. Shah, P.; Murthy, C. Studies on the porosity control of MWCNT/polysulfone composite membrane and its effect on metal removal. J. Membr. Sci. 2013, 437, 90-98. [CrossRef] 